\title{
On the Integration Frame of Collaborative Innovation Support System for Telecom Operators
}

\author{
Jing Zhang \\ School of Economics and Management, Beijing University of Posts and \\ Telecommunications, Beijing 100876, P.R. China andiezhang2005@yahoo.com.cn
}

\begin{abstract}
As the industry value-chain getting complicated, collaborative innovation becomes an important competitive factor for telecom operators. However, collaborative innovation means more participators and greater uncertainty in the innovation procedure. As a result, collaborative innovations usually cost more in time and money, which could make the innovations lose or bring serious problems even when new services have been launched into the market. In this paper, the integration frame of collaborate innovation support system (CISS) is put forward. Firstly, the participants and resource flows in the collaborative innovation in telecom industry are analyzed. Based on that, the requirements and functions of CISS are summarized. The system should help to connect the necessary resources for innovations and implement process management in an efficient way. Secondly, the framework of CISS is designed, defining functional construction and information flows. Then the key technologies supporting CISS are illustrated. Functionally, the CISS should be a part of BSS/OSS (Business/Operating Support System), and the relationship between CISS and BSS/OSS is explained. Finally, the organizational and managerial supports for the system are discussed.
\end{abstract}

Keywords: Collaborative Innovation, Telecom Operator, Data Integration, OSS, CISS

\section{COLLABORATIVE INNOVATIONS IN THE TELECOM INDUSTRY}

The reform in the telecom industry has brought telecom operators drastic competition as well as more opportunities to spread services. Today, the importance of innovation can't be overestimated. But the fact that the industry value-chain is getting complicated is bringing more difficulties in innovation management of the operators. As telecom operators are providing more information services, they have to implement collaborative innovations, which need the cooperation from all the participants in the telecom industry value-chain. As shown in Fig. 1, telecom operators play as a bridge between customers and other providers. They adopt the equipments, software, contents and applications, integrate them into services and then provide the services to customers. On the other side, because they directly connect with customers, telecom operators should analyze the demand of customers, originate innovations and implement the work together with other providers.

Please use the following format when citing this chapter:

Zhang, J., 2007, in IFIP International Federation for Information Processing, Volume 255, Research and Practical Issues of Enterprise Information Systems II Volume 2, eds. L. Xu, Tjoa A., Chaudhry S. (Boston: Springer), pp. 1111-1116. 


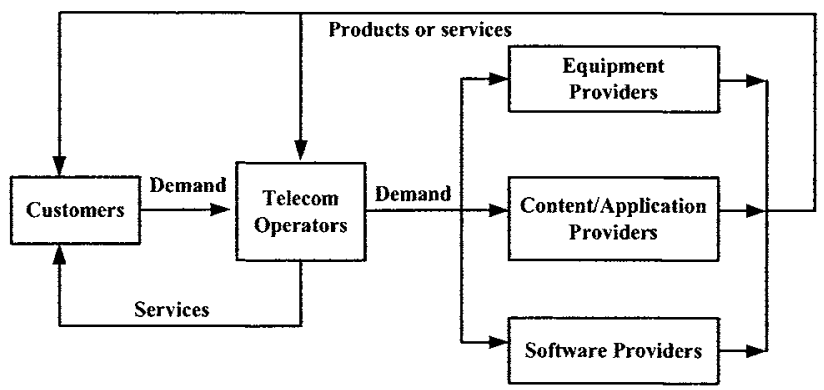

Figure 1. The Relationships Between the Participants in Collaborative Innovations in The Telecom Industry [1]

However, collaborative innovations usually cost more in time and money. More participants undoubtedly need more communications and then generate plenty of transaction costs. The greater uncertainty possibly leads to information reveal and makes the innovation out of control. Therefore, telecom operators need to mange collaborative innovations in a more effective and efficient way. Since telecom operators provide information-centered services, and information plays an essential role in the innovation procedure, an information system for innovation management could be a powerful tool. In the following sections, the Collaborative Innovation Support System (CISS for short) is put forward, and the functions, integration frame, and key technologies of it are described.

\section{THE INTEGRATION FRAME OF CISS}

\subsection{General System Requirements}

CISS aims at connecting all the participants, converging the relative information from different sources, making integrative analysis on the data, and supporting the decision-making and management of innovation, especially of collaborative innovation. Basically, CISS is an information system, and the general requirements of CISS that should be considered are listed as follows.

(1) CISS should provide standard interface by which it could exchange data with the intranet and extranet of the company. Then the available information relative to innovation can be collected quickly.

(2) CISS should be able to process number, text and figure systematically. By filtering, classifying, refining, querying, comparing, analyzing and updating several types of data, CISS should output and display the data in a specific and clear way.

(3) CISS should provide friendly human-machine interface and multilevel license management to protect the data. The top manager, project manager and other participants of innovation can access different part of the system. 


\subsection{The Functions of CISS}

It is expected that the telecom operator depending on CISS can master the change of environment more accurately, discover the problems in innovation procedure in time, and improve the ability to innovate continuously over the long run. To succeed in these objectives, the functions of CISS include four aspects.

(1) Decision-making support for strategic selection of innovation. At the beginning of innovation, the top manager of innovation often has to determine: (a) what project to be selected, (b) when to launch the new services or deploy new technology, and (c) how many resources should be input? To help the manager answer these questions, CISS should collect the information about the company's environment and competencies. Furthermore, based on powerful data processing capacity, CISS should provide key indicators monitoring, forecasting, integrative analyzing and reporting to help the manager discover the innovation ideas. In the future, CISS could be more intelligent by integrating expert system and learning system.

(2) Supplier/partner relationship management. The suppliers or partners are all potential participants of collaborative innovations. But to make sure that collaborative innovation can be implemented in a fluent way, it is reasonable to choose several suppliers/partners and build long-term cooperation with them. Therefore CISS should keep the data about the credit, resources, capability of the main partners, make evaluation of the quality of suppliers and partners, and give suggestion on choosing the most capable suppliers/partners for certain collaborative innovation.

(3) Innovation project management. The selected innovation project will start after decision-making. Project management includes developing a project plan, specifying tasks, and associating budgets and timelines for completion. It also includes implementing the project plan, along with careful controls. In collaborative innovations, some tasks have to be appointed to suppliers or partners. CISS should provide a uniform interface for the participants to report how the project is getting along. Then the project manager can master the dynamics in the innovation procedure, and give control when it is necessary.

(4) New service designing and testing platform. To provide a new service, telecom operators must design the function, characteristics, quality standard, resource configuration, price and tariff schemes, and procedures of the service. In collaborative innovation, many business entities contribute to the end service, and the service design is more complicated. The new service designing and testing platform in CISS provides an environment where new services be designed, generated, and tested in a small range.

The four aspects above are not independent. They interact with each other and construct the integration frame of CISS, as shown in Fig. 2.

\section{THE KEY TECHNOLOGIES OF CISS}

Because CISS is expected to provide powerful support for innovation management, except the ordinary technologies of database, system analysis and interface design, it needs advanced data processing technologies. The key technologies include data warehouse, data mining and data visualization. 
(1) Data warehouse is defined as a subject-oriented, integrated, non-volatile and time-variant collection of data designed to support management decision making for the companies [2]. It is different from relational database, but it should work with existing database. CISS picks the relative data out from source database, and transforms them to analytical data, and stored them in data warehouse. The core of data warehouse technology is the way of data storage and management, and OLAP (On-Line Analytical Processing) server, providing multidimensional analysis.

(2) Data mining is a class of database applications that look for hidden patterns in a group of data that can be used to support decision-making. For example, the telecom operator can predict the possible response from the market to a new service, by applying data mining in the historical data of service usage data. Obviously, it is significant in innovation management. Data mining tools should be an important part of CISS.

(3) Data visualization is the process of representing abstract data as images that can aid in understanding the meaning of the data [3]. It is essentially a mapping process from computer representations to perceptual representations, choosing encoding techniques to maximize human understanding and communications. Collaborative innovations have to gather and generate plenty of information and knowledge and exchange them between the participants. Visualization helps managers find the structure, features, patterns, trends and abnormal conditions from data.

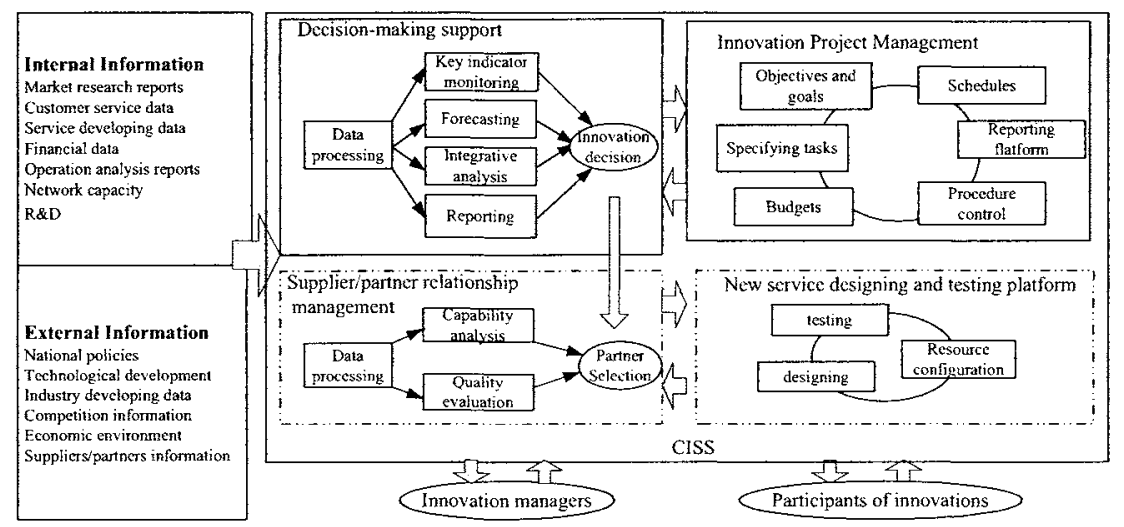

Figure 2. The Integration Frame of CISS

\section{THE RELATIONSHIPS BETWEEN CISS AND BSS/OSS}

In the recent years, telecom operators all invest great in building BSS/OSS (Business/Operation Support System). BSS/OSS enables telecom operators to manage, monitor and control the service procedures and telecom networks. Customer care system, charging and billing, ordering services, network element and network management are all parts of BSS/OSS $[4,5]$. BSS/OSS also has the subsystem of operation analysis, providing decision-making support. But currently, BSS/OSS mainly focuses on the operation of existing services and networks. Since innovation is 
future-oriented, BSS/OSS can't give special support for innovation. That is why CISS is put forward.

But BSS/OSS is expanding its functions. It is expected that BSS/OSS will provide more functions for service operation and management, including handling new customers, introducing new services and changing existing ones. Therefore, CISS functionally should be a part of BSS/OSS in the future. Now CISS should work together with BSS/OSS. Plenty of data are shared between the two systems. When a new service is proved to be able to operate well in CISS, it should be loaded into BSS/OSS and put into normal operation.

\section{ORGANIZATIONAL AND MANAGERIAL SUPPORTS FOR CISS}

It should be emphasized that CISS is just a tool for innovation management. Without organizational and managerial supports, CISS can't work at all.

First of all, the telecom operator should craft innovation strategy as an important part of corporate strategy. Then the company should establish the department of innovation and define its responsibility clearly. And the principles and rules of innovation procedure management should be defined. These are the basis of CISS. Especially, to make sure that relative and valuable information can be picked and input into CISS, there must be some "information gatekeepers". An information gatekeeper should be a person who is sensitive to the change of policies, market demand and technology development, and other information relative to innovations. In CISS, some data come from BSS/OSS or other existing information system, but some information need to be input manually. The information gatekeeper will keep the useless, invalid and false information out of CISS. In addition, CISS requires that the managers and participants to understand the relative information technologies well.

\section{REFERENCES}

1. J. Zhang and X. Liang, Directions of Telecom Service Innovation, China Communications. Volume 2, Number 2, pp.56-62, (2005).

2. W.H. Inmon, Building the Data Warehouse (John Wiley \& Sons, Inc.: New York, NY, 1996).

3. X. Li and P. Zhang, On the Integration Frame of Web-based Team Creation Support System, System Engineering (China). Volume 22, Number 5, pp.76-80, (2004).

4. NGOSS GROUP. Enhanced Telecom Operations Map (eTOM)[S]. The Business Process Framework, ver 3.0, TMF GB921 (2002).

5. H. Zhao and H. Li, Research on BSS/OSS Models for Telecom Operators, Journal of University of Electronic Science and Technology of China. Volume 31, Number 4, pp.379-382, (2002). 